\title{
Complexos temáticos na formação de professores do campo ${ }^{1}$
}

\section{Thematic complexes in teacher training in field education}

\author{
Maria Bernadete de Melo Cunha ${ }^{2}$ \\ José Luis de Paula Barros Silva²
}

\begin{abstract}
RESUMO
Neste artigo procuramos mostrar os significados atribuídos pelos estudantes do curso de Licenciatura em Educação do Campo/Universidade Federal da Bahia acerca do Sistema de Complexos Temáticos no trabalho docente. Empregando abordagem de natureza qualitativa, foram coletados e analisados dados por meio de dois planejamentos de ensino elaborados pelos estudantes, utilizando temas do Sistema de Complexos. Entre eles, realizamos entrevistas individuais semiestruturadas para complementar os dados. Os resultados mostram que o Sistema de Complexos Temáticos foi parcialmente incorporado à práxis pedagógica desses estudantes e que houve avanços em relacionar o ensino de conteúdos científicos escolares a questões sociais relevantes, contribuindo para uma melhor compreensão da realidade. Embora os resultados sejam positivos, as dificuldades encontradas durante a formação apontam para a necessidade de se lutar por condições de trabalho nas Instituições de Ensino Superior que possibilitem outros modos de ensinar e formar professores, promovendo sua educação continuada de modo permanente.
\end{abstract}

Palavras-chave: educação do campo; formação de professores; Sistema de Complexos Temáticos.

\footnotetext{
ABSTRACT

In this article we intend to show meanings assigned by students of the Teacher Training Course in Field Education/Universidade Federal da Bahia about

DOI: $10.1590 / 0104-4060.45967$

1 Este artigo tem como base a tese de doutoramento de um dos autores. (CUNHA, 2014).

2 Universidade Federal da Bahia. Instituto de Química. Salvador, Bahia, Brasil. Rua Barão de Jeremoabo, s/n ${ }^{\circ}$, Campus Universitário de Ondina. CEP: 40.170-115. E-mail: berna.dete@uol. com.bre joseluis@ufba.br
} 
a Thematic Complexes System in their teaching work. Using a qualitative approach, data were collected and analyzed trough two teaching plans prepared by students, using themes from the Complexes System. Between them, we made individual semi-structured interviews to complement data. Results show that the Thematic Complexes System was partially incorporated into the pedagogical praxis of these students and that there have been improvement in relating teaching of school science content with relevant social issues, concurring to a better understanding of reality. Although results are positive, difficulties met during the training process point out the need to fight for working conditions in Higher Education Institutions that allow other ways of teaching and training teachers, promoting their continuing education permanently.

Keywords: field education; teacher training; Thematic Complexes System.

\section{Introdução}

As diretrizes para formação de professores e professoras do país (BRASIL, 2002, 2015), assim como pesquisadores na área da educação (LIMA; PAULA; SANTOS, 2009; MENEZES NETO, 2009; MORADILLO, 2010; ROCHA, 2009), indicam a necessidade da implementação de perspectivas inovadoras para essa formação, o que, em nossa opinião, pressupõe superar a matriz curricular de base empírico-analítica, que apresenta a ciência de forma ritualista, não histórica, com características eminentemente técnicas. A questão que se coloca é como devem ser formados os professores e professoras e de que ponto de vista teórico deve se dar tal formação.

Ferreira e Kasseboehmer (2012) categorizam as concepções de formação de professores, como: profissional técnico, profissional prático e intelectual crítico. Tais concepções têm recebido críticas por pesquisadores das correntes mais diversas da área da educação. (CARVALHO; GIL-PÉREZ, 2011; DUARTE, 2003; GATTI, 2010; LEITE, 2012; MALDANER, 2003; ROSSO et al., 2010; SAVIANI, 2009).

Por outro lado, encontramos proposições para a formação de professores e professoras em perspectiva marxista, a exemplo de Kuenzer (2012) e Saviani (2011), entre outros. Kuenzer (2012) defende que o currículo de formação de professores tem papel fundamental para estabelecer quais concepções ontológicas e epistemológicas serão tratadas, resultando em concepções de trabalho, de ser humano e de sociedade, que estarão presentes nos projetos pedagógicos. Desse modo, a formação de professores necessita articular conhecimento sobre 
o mundo do trabalho, científico-tecnológicos específicos e pedagógicos, além da formação em pesquisa e experiências no trabalho e na educação.

Saviani (2011) destaca a necessidade da colaboração entre as instituições formativas e aquelas em que irão atuar os futuros profissionais, organizando a formação a partir da maneira como as escolas da Educação Básica funcionam, de modo a articular teoria e prática, conteúdo e forma, conhecimento de referência e pedagógico, propondo a Pedagogia histórico-crítica.

É nessa vertente que se insere o curso de Licenciatura em Educação do Campo oferecido pela Universidade Federal da Bahia (UFBA) como curso piloto, entre 2008 e 2013, e que foi objeto desta investigação. O currículo e o trabalho pedagógico foram fundamentados em princípios filosóficos do materialismo histórico-dialético, compreendendo a educação como processo permanente de formação e transformação humana e social.

A Educação do Campo faz parte das reivindicações de camponeses organizados em movimentos sociais com envolvimentos diferenciados na luta de classes, tendo em comum a unidade na luta contra o capital, pelo direito à terra, ao trabalho e ao conhecimento.

Associando a luta pela reforma agrária com a luta pela educação, adotam como suas reivindicações básicas a correção das desigualdades de escolarização no campo, a universalização do acesso à Educação Básica, a melhoria da situação das escolas do campo e a formação de professores e professoras. (CARVALHO, 2011). É, portanto, a "luta histórica contra os processos de exclusão social" (PEIXER; VARELA, 2011, p. 13) o que faz movimentar os seus interesses.

Durante o desenvolvimento da Licenciatura em Educação do Campo/ UFBA, buscou-se unir a proposição de organização do ensino com a forma de se trabalhar este ensino, visando alcançar o objetivo de:

Formar professores para os anos finais (segundo segmento) do Ensino Fundamental e Ensino Médio em consonância à realidade social e cultural específica das populações que trabalham e vivem no e do campo, na diversidade de ações pedagógicas necessárias para concretizar [a educação] como direito humano e como ferramenta de desenvolvimento social. (UNIVERSIDADE FEDERAL DA BAHIA, 2008, p. 26).

Os docentes formados deveriam atuar com o conhecimento produzido pela humanidade, baseado no referencial teórico e crítico, no sentido de contribuir para a superação do projeto histórico capitalista. 
Coerentemente com o referencial filosófico, adotou-se o Sistema de Complexos Temáticos (PISTRAK, 2008) como parte das orientações pedagógicas do curso, constituindo-se em um processo formativo sem igual até o momento.

Entendendo que o currículo da licenciatura pode e deve influenciar a prática social dos professores/professoras formados, este artigo tem como objetivo apresentar como ocorreu a incorporação do Sistema de Complexos Temáticos no trabalho docente dos estudantes da Licenciatura em Educação do Campo/UFBA.

\section{O Sistema de Complexos Temáticos}

O Sistema de Complexos Temáticos foi discutido por Pistrak (2008), educador do período pós-revolução russa, como o modo adequado para os jovens estudarem e compreenderem as relações entre os objetos e fenômenos da realidade em sua dinâmica dialética e de acordo com a teoria marxista:

Estuda-se a realidade atual pelo conhecimento dos fenômenos e dos objetos em suas relações recíprocas, estudando cada objeto e cada fenômeno de pontos de vista diferentes. O estudo deve mostrar as relações recíprocas existentes entre os aspectos diferentes das coisas, esclarecendo-se a transformação de certos fenômenos em outros, ou seja, o estudo da realidade atual deve utilizar o método dialético. Apenas um conhecimento da realidade atual deste tipo é um conhecimento marxista.

Daí deriva a necessidade de organizar as disciplinas do programa em complexos, na medida em que este é o único sistema que garante uma compreensão da realidade de acordo com o método dialético. A partir dessa compreensão, o sistema de complexos deixa de ser para nós apenas uma boa técnica de ensino, para ser um sistema de organização do programa justificado pelos objetivos da escola. (PISTRAK, 2008, p. 134, grifos do autor).

Claro está que se trata de um sistema para a organização das disciplinas e dos conteúdos programáticos, vinculado aos objetivos educacionais e não de um método de ensino. Um complexo, então, constitui-se num "centro de interesse" (PISTRAK, 2008, p. 131) a partir do qual se desenvolvem os conhecimentos necessários ao estudo e à compreensão da realidade.

O termo complexo reflete o reconhecimento de que a realidade não é simples e que suas diversas partes se encontram interligadas num todo (CUNHA; 
SILVA; MORADILLO, 2013), um ponto de vista coerente com a posição filosófica crítica.

Um Sistema de Complexos é constituído por vários centros de interesse inter-relacionados. A escolha do tema de um complexo é guiada pelos objetivos educacionais definidos no projeto pedagógico da escola ou curso. Por isso, o objeto que determina o tema do complexo deve ser "[...] um fenômeno de grande importância e de alto valor enquanto meio de desenvolvimento da compreensão das crianças sobre a realidade atual". (PISTRAK, 2008, p. 135). Tal importância deriva do caráter social do fenômeno e, não apenas, de sua adequação pedagógica, visto que se busca o estudo da realidade.

Este Sistema deve possuir uma forte vinculação entre suas partes - diferentes subtemas - unificadas pelas relações com o tema que lhe dá fundamento. Os complexos do sistema precisam ser organizados de modo a ampliar gradativamente a compreensão dos estudantes acerca da realidade.

O estudo do tema de um complexo ocorre de modo encadeado com os temas de outros complexos, visando alcançar níveis mais gerais de entendimento dos fenômenos. Tal encadeamento requer recobrimento parcial dos temas, de modo que elementos comuns possibilitem a articulação dos complexos do sistema.

A organização didática deve considerar o nível de ensino - fundamental, médio, superior: quanto mais elevado, maior o aprofundamento e a generalidade do conteúdo. Tal critério possibilita que, à medida que os estudantes se desenvolvam, possa haver o desdobramento do tema do complexo em subtemas e conhecimentos que possibilitam conduzi-los a uma compreensão da realidade com maior amplitude e profundidade. É imprescindível que as relações entre os conhecimentos estudados estejam claras e acessíveis para os estudantes, de acordo com o nível de ensino.

No caso do Ensino Médio e do Ensino Superior, os componentes curriculares possuem caráter específico e costumam ser ensinados por diferentes professores. Tal fato pode dificultar a organização do ensino pela dispersão dos conteúdos entre disciplinas e docentes distintos. A principal diretriz a ser seguida é que as disciplinas devem estar subordinadas ao tema do complexo, ou seja, cada qual contribuindo para a ideia fundamental do complexo em foco, fundindo-se nele. Desse modo, as disciplinas se organizam visando o objetivo do complexo e, consequentemente, o objetivo do curso. (PISTRAK, 2008).

Pistrak (2008) sugere que o planejamento do ensino se realize por etapas: definido um complexo, os professores das disciplinas avaliam como cada uma pode contribuir para a compreensão das ideias envolvidas, como se relacionam no processo de ensino e, então, elaboram planos disciplinares que virão a compor um plano de trabalho global. Trata-se de um trabalho coletivo, que exige mútua 
responsabilidade dos docentes das disciplinas, no sentido de trabalharem os temas de modo articulado e encadeado, explorando tanto as especificidades das disciplinas quanto suas interfaces, realizando avaliações periódicas do ensino e eventuais correções do planejamento.

É esperado que os estudantes desenvolvam consciência do trabalho de ensino através do complexo e das contribuições das disciplinas:

As ciências não se fecham em si mesmas; o sentido dos estudos científicos deve ser compreendido não no término do ensino, mas durante o próprio ensino. Enfim, o sistema de complexos pressupõe (e é uma hipótese justa) que cada disciplina escolar analisa uma parte determinada de uma matéria geral concreta, propondo-se, antes de tudo, dar ao aluno o domínio dos métodos experimentais próprios das ciências. (PISTRAK, 2008, p. 153).

Por fim, o ensino por meio do Sistema de Complexos deve possibilitar que os estudantes sejam capazes de analisar a realidade por meio do método dialético, desenvolvendo autonomia para a realização da sua atividade em sociedade.

\section{O Sistema de Complexos Temáticos na Licenciatura em Educação do Campo/UFBA}

O Projeto Político-Pedagógico do curso de Licenciatura em Educação do Campo/UFBA propõe a “[...] organização dos componentes curriculares por áreas de conhecimento e trabalho pedagógico interdisciplinar", bem como toma "[...] a realidade como base da produção do conhecimento - a prática social como ponto de partida e chegada" e a discussão de "conteúdos formativos socialmente úteis" (UNIVERSIDADE FEDERAL DA BAHIA, 2008, p. 24, passim), adotando o trabalho pedagógico a partir do Sistema de Complexos Temáticos.

A aplicação do Sistema de Complexos Temáticos em um curso de formação de professores se justifica pela compreensão de que tal fato pode contribuir para superar as contradições existentes nos currículos, a exemplo de: separação entre teoria e prática, descontextualização e perda da historicidade dos conteúdos, assim como, falta de aplicação do conhecimento trabalhado em situações concretas. Verifica-se a necessidade de superar o trabalho pedagógico ainda organizado de forma linear (modelo taylorista), em que cada professor se responsabiliza 
em transmitir um dado conteúdo fragmentado. Com a organização do currículo em complexos temáticos, procura-se realizar uma proposta curricular intensiva, dialógica e dinâmica. Como os complexos estão embasados no plano social, possibilitam aos estudantes, além da percepção crítica real, uma intervenção ativa na sociedade, com seus problemas, interesses, objetivos e ideais. (TAFFAREL; COLAVOLPE, 2009).

No caso do curso de Licenciatura em Educação do Campo/UFBA, os complexos visavam ampliar a compreensão da realidade com o objetivo de formar professores para a educação do campo. Não se trata de crianças, mas de adultos em processo de formação profissional. Considerando que a educação seja "[...] uma forma de ação político-social que não se limita a interpretar o mundo, mas que procura, pela prática educativa, desenvolver uma ação transformadora do real" (UNIVERSIDADE FEDERAL DA BAHIA, 2008, p. 32), definiu-se um sistema formado por quatro complexos, cada qual relativo a um conjunto de fenômenos sociais:

\section{Complexo Temático I - Ser Humano e sua Relação com a Natureza/ Terra \\ Fenômenos Sociais - O homem e o trabalho na terra como fenômenos determinados por múltiplas relações a uma série de fenômenos análogos, enraizados na vida social.}

Complexo Temático II - Ser Humano e sua Relação com o Trabalho Fenômenos Sociais - A terra e o trabalho do homem como processo de produção material e social da vida.

Complexo Temático III - Ser Humano e as Relações com a Sociedade Fenômenos Sociais - A terra, o trabalho do homem e sua produção determinantes das relações sociais e culturais.

\section{Complexo Temático IV - Ser Humano e Educação}

Fenômenos Sociais - A necessidade de apropriação da cultura humana historicamente construída. (UNIVERSIDADE FEDERAL DA BAHIA, 2008, p. 43-44).

Para a área de Ciências da Natureza e Matemática foi, posteriormente, escolhido o Sistema de Complexos Recursos Socionaturais, tendo como temas: Água, Ar atmosférico, Solos, Metais, Alimentos, Energia e Resíduos Sólidos. Tais complexos precisariam ser trabalhados pedagogicamente com base numa concepção de ciências que explicitasse sua dimensão lógica e histórica, ou seja, numa abordagem contextual em que se buscasse a história e a filosofia das ciências no ensino dos conceitos científicos. (FREIRE JUNIOR, 2002). 
A organização curricular da Universidade Federal da Bahia é, preponderantemente, disciplinar e as disciplinas são oferecidas pelos departamentos. Não foi possível criar novos componentes curriculares para o curso, nem contratar professores com formação mais próxima dessa proposta pedagógica, o que dificultou operar com o Sistema de Complexos.

Em cada módulo, foi explicada a organização curricular por complexos e áreas de conhecimento aos professores envolvidos que, em grande parte, tiveram dificuldade em vincular os conteúdos disciplinares aos temas dos complexos. Vários professores formadores não compreendiam o curso em sua totalidade, restringindo-se à sua disciplina, e os conteúdos foram ensinados de modo fragmentado. (GAMA, [2010?]). Contudo, os docentes formuladores da proposta pedagógica trabalharam os complexos com os estudantes em suas disciplinas, sendo discutidas as obras de Pistrak: Fundamentos da Escola do Trabalho (PISTRAK, 2008) e A Escola Comuna (PISTRAK, 2009).

Três disciplinas da área Ciências da Natureza e Matemática foram desenvolvidas, explicitamente, à luz do Sistema de Complexos Temáticos: Química

Geral I, com os temas Água, Solos e Ar atmosférico; Química Fundamental III (Físico-Química), com o tema Energia; e Química Orgânica nas Ciências Naturais, com o tema Alimentos.

\section{Metodologia}

Adotamos uma linha de investigação qualitativa, no sentido de compreender os significados atribuídos pelos estudantes da Licenciatura em Educação do Campo/UFBA ao Sistema de Complexos Temáticos no âmbito das atividades docentes.

Participaram da pesquisa 13 estudantes que escolheram Ciências da Natureza e Matemática como área específica de formação. A seleção desses estudantes como sujeitos da pesquisa se justifica pelo fato de um de nós (CUNHA, 2014) tê-los acompanhado como docente ao longo de todo o desenvolvimento do curso. Esses estudantes, em sua maioria, são professores/professoras do Ensino Fundamental, em escolas do campo de duas regiões do estado da Bahia: Recôncavo e Nordeste. Neste artigo, foram-lhes atribuídos nomes fictícios, visando preservar as suas identificações, conforme estabelecido em Termo de Consentimento Livre e Esclarecido assinado pelas partes envolvidas. 
Os dados foram coletados durante o último período do curso, considerado como o momento do retorno à prática social, movimento final do processo pedagógico histórico-crítico proposto por Saviani (2009). Foi solicitada a realização de duas atividades de planejamento de ensino, intercaladas por uma entrevista, com o objetivo de investigar como ocorreu a incorporação do Sistema de Complexos Temáticos no trabalho docente desses estudantes. Procedeu-se, simultaneamente, à observação dos estudantes durante o trabalho e registraram-se seus atos por meio de anotações e gravações. A coleta de dados foi iniciada com uma apresentação oral da primeira atividade, que consistiu na elaboração de duas sequências didáticas, compreendidas como conjuntos de aulas, com base em dois dos temas que compunham o Sistema de Complexos Recursos Socionaturais: Água, Solos, Ar Atmosférico, Resíduos Sólidos, Metais e Energia. O tema Alimentos foi excluído por ter sido trabalhado em uma das disciplinas e utilizado por alguns estudantes no estágio curricular.

A atividade foi realizada em dois turnos de quatro horas, sem consulta a qualquer fonte. No primeiro turno, foi orientado o que os planos de aulas deveriam conter: apresentação, tema, justificativa, objetivo geral e objetivos específicos, conteúdos, recursos e avaliação de cada aula. Cada item explicado, a título de revisão de conteúdos ensinados anteriormente. A metodologia de ensino foi deixada à livre escolha, porém, as propostas deveriam ser justificadas com base no Sistema de Complexos da área. O material elaborado pelos estudantes foi recolhido para análise posterior.

No momento seguinte foi realizada entrevista semiestruturada com cada um dos estudantes, visando esclarecer o emprego do Sistema de Complexos Temáticos em seus planejamentos. Algumas questões foram elaboradas com base nos resultados individuais da primeira atividade e novos questionamentos surgiram durante as entrevistas, que foram gravadas e transcritas, para fins de análise e esclarecimento de aspectos do material escrito.

Durante sua realização foi possível manter um clima de confiança entre os envolvidos por se tratar de pessoas conhecidas e comprometidas com o curso.

Após a realização das entrevistas, foi devolvido o material escrito com as sequências didáticas propostas por cada estudante no primeiro momento para que revissem, corrigissem, se fosse o caso, dessa vez utilizando consulta a qualquer fonte, fosse referência teórica ou material didático. Assim, foi feita uma nova versão das sequências didáticas com os mesmos temas escolhidos anteriormente, desta vez, registradas em formulários, que foram entregues à pesquisadora para análise. 


\section{Análise de dados e resultados}

\section{Planejamento de ensino: primeiro momento}

A distribuição dos temas escolhidos pelos estudantes para o planejamento das sequências didáticas na primeira atividade ocorreu de modo desigual, conforme mostra o Quadro 1.

QUADRO 1 - QUANTIDADES DE ESTUDANTES POR TEMAS ESCOLHIDOS PARA AS SEQUÊNCIAS DIDÁTICAS

\begin{tabular}{|c|c|c|c|c|}
\hline Tema & Quantidade & & Tema & Quantidade \\
\hline Água & 11 & & Ar Atmosférico & 02 \\
\hline Solos & 05 & & Resíduos Sólidos & 02 \\
\hline Energia & 05 & & Metais & 01 \\
\cline { 1 - 1 } & & &
\end{tabular}

FONTE: Os autores (2016).

Nota-se a predominância da escolha do tema Água sobre os demais, o que pode ser atribuído à sua melhor aprendizagem, por ter sido trabalhado durante mais tempo e em mais detalhe que os demais temas. De fato, o tema Água serviu como contexto para a introdução de vários conceitos químicos básicos, sendo repetidamente citado e explorado. Um dos livros utilizados para estudo pelos alunos contém o dobro de páginas relativas ao tema Água em comparação com os temas Ar Atmosférico e Solos. Junte-se a isso a realização de visita a uma estação de tratamento d'água, a partir da qual foram discutidos aspectos químicos e questões de importância social relacionadas à água. Os estudantes também realizaram trabalhos sobre o tratamento de água em seus municípios de origem, valorizando o tema como contexto de ensino-aprendizagem.

Em segundo lugar na preferência estão os temas Solos e Energia. A escolha de Solos como tema pode ser explicado pela aproximação dos estudantes com o uso do solo no seu cotidiano, por serem professores de escolas situadas no campo. Uma atividade importante foi o estudo sobre o uso e o aproveitamento do solo, considerando a questão agrária nas localidades de origem dos estudantes, o emprego de agrotóxicos e a qualidade dos solos.

A escolha da Energia pode ser atribuída ao fato de ser um tema de claro interesse social e que foi trabalhado em outra disciplina de Química, na qual os estudantes discutiram o planejamento a ser aplicado no Ensino Médio.

Os demais temas - Ar Atmosférico, Resíduos Sólidos e Metais - foram menos explorados ao longo do curso e, talvez por isso, mobilizaram menos os estudantes.

A totalidade dos estudantes não se referiu ao Sistema de Complexos, em geral, ou ao complexo da área de Ciências da Natureza, Recursos Socionaturais. 
Apenas duas estudantes - Leila e Lia - citaram os Recursos Socionaturais, sem explicar quais relações tinham com os temas escolhidos. Tais fatos sugerem que os planejamentos de ensino não se encontravam claramente referenciados pela teoria do Sistema de Complexos. De fato, o emprego de temas no ensino foi uma exigência da atividade proposta e não uma iniciativa dos licenciandos.

Por outro lado, dez dos treze trabalhos mostraram um vínculo claro com uma característica necessária dos complexos: relevância social do tema. Por exemplo, Gilberto se referiu à Água como "um bem natural de relevância social" e propôs discutir falta de água potável, formas de acesso à agua, desperdício; Jacira justificou a escolha do Ar Atmosférico como tema, para "destacar a importância que o ar exerce para todos os seres vivos, valorizando as diversas formas que através dele se possibilita dar continuidade à vida". Nelson definiu o objetivo do ensino do tema Solos como "instigar os educandos a buscar maneiras de conservação e proteção do solo e assim como usar o solo em beneficio da humanidade", justificando que o "ser humano [...] depende do solo para sua sobrevivência, cabe [...] buscar compreender, cuidar e manter o solo bem protegido contra as impurezas tóxicas quanto à sua degradação causada por fatores climáticos". Paulo considerou que o tema Energia "apresenta uma possibilidade concreta de questionar os alunos sobre seu valor social, seu valor comercial e seu valor para o desenvolvimento da vida nesta sociedade capitalista". Acrescentou ainda que o tema "vincula-se diretamente com o tema petróleo e energia renovável onde teremos uma oportunidade de ligar o lógico com o histórico e compreender como este processo se dá na sociedade burgue$s a$ ". Como se pode notar, os estudantes relacionaram o ensino dos conteúdos a aspectos sociais de grande importância, tanto na cidade quanto no campo.

Consideramos que, em um primeiro momento, os estudantes não demonstraram conhecimento integral acerca do conceito de Sistema de Complexos, apesar de se referirem a questões sociais, uma vez que: não citaram o termo complexo; não estabeleceram relações claras entre os diversos conteúdos planejados e os aspectos sociais indicados. Tampouco exploraram conteúdos das Ciências Naturais - Química, Física, Biologia ou, mesmo, Matemática em conexão com os temas escolhidos. As dificuldades para a elaboração das sequências didáticas foram justificadas por não ter havido consulta a materiais didáticos: Maíra, por exemplo, reclamou várias vezes, durante a atividade, que "nunca tinha visto professor fazer planejamento sem consulta", no que foi acompanhada por vários colegas. É claro que a consulta é sempre necessária quando se planeja uma aula, porém, seria de esperar que os licenciandos tivessem um conceito de complexo mais bem estabelecido e uma visão geral dos conteúdos que possibilitassem melhor realização das sequências didáticas solicitadas. Este 
comportamento aponta certa fragmentação do pensamento dos estudantes, bem como pouca autonomia em relação aos materiais didáticos prontos.

Enfim, esperava-se que houvesse maior conexão entre os conteúdos das ciências naturais e a organização por complexos, pois a relevância dos conteúdos para o desenvolvimento humano foi ressaltada durante todo o curso. Contudo, os resultados não podem ser considerados totalmente surpreendentes, em vista das dificuldades de parte dos professores do curso em adotar a organização curricular por complexos.

\section{Entrevista: segundo momento}

Foram realizadas entrevistas individuais. De início, questionamos em relação ao Sistema de Complexos - "O que é um Sistema de Complexos Temáticos?" - que foi pouco apresentado nas sequências didáticas. A maioria dos estudantes não sabia explicar a noção de complexo, indicando a dificuldade que estavam encontrando em relacionarem o que havia sido discutido teoricamente com a possibilidade de aplicação desses conhecimentos.

Entretanto, Lia declarou: "são coisas palpáveis, visiveis na sociedade. Não é qualquer tema importante para a minha escola, para a sua escola, mas, para a humanidade". Paulo reconheceu que "não é qualquer um [tema]; se não for de caráter social, não tem validade o complexo". Nelson não conseguiu conceituar complexo, porém, sabia que Pistrak havia proposto o Sistema de Complexos Temáticos e que discutiu "a relação do sujeito com seu contexto social". Cosme respondeu que o ensino baseado nos complexos "não trata só o conteúdo de Química, mas, trata as questões sociais".

Um fato importante é que todos lembravam que o Sistema de Complexos havia sido proposto por Pistrak e em qual momento sócio-histórico, bem como recordavam discussões desta referência ao longo do curso. Contudo, admitiram não se lembrar do Sistema de Complexos da área de Ciências da Natureza e Matemática: os Recursos Socionaturais, assim como de seus temas componentes. Houve mesmo quem não reconhecesse o significado da expressão recursos naturais, embora outros, quando estimulados pela pesquisadora, houvessem reagido afirmando que os objetos que dão origem aos temas - água, ar, etc. "são recursos naturais".

A dificuldade de aplicação da teoria à prática foi evidente. Segundo Maíra, "A gente está com o conhecimento solto ainda e não consegue saber onde encaixa. [...] O complexo temático é ter um tema e a partir dai eu consigo estabelecer relações com o conteúdo". As sequências didáticas mostram que esta constatação individual poderia representar o pensamento da turma como um todo, dada a falta de referência aos complexos. Percebe-se o equívoco de Maíra: empregar 
o tema do complexo como um modo de chegar aos conteúdos de ensino, mas o tema do complexo não pode servir de pretexto ao ensino de conteúdos escolares. O conceito de complexo implica em que o tema seja selecionado com base na sua importância para a compreensão da realidade - objetivo maior do ensino - e, desse modo, os diversos conteúdos que esclarecem e explicam o tema tornam-se conteúdos escolares que possibilitam maior e melhor compreensão da realidade.

As falas dos estudantes durante as entrevistas estão em pleno acordo com os planejamentos de ensino escritos. Parece evidente que a articulação entre teoria e prática deixou a desejar, o que não se constitui num fato exclusivo deste curso, mas de um princípio da formação de professores insistentemente buscado e dificilmente realizado.

\section{Replanejamento de ensino: terceiro momento}

Após as entrevistas, foram-lhes devolvidos os primeiros planejamentos realizados e solicitado que fossem revistos, desta vez, utilizando material de consulta, que consistiu de livros didáticos de Química para o Ensino Médio aprovados no Programa Nacional do Livro Didático (PNLD)/2011, o livro de Pistrak (2008) e sítios da internet. Esta atividade durou dois turnos de quatro horas.

Notamos que, de modo geral, houve uma mudança significativa nos planejamentos, mostrando conteúdos que podem ser abordados por diferentes disciplinas e apontando uma perspectiva sócio-histórica, o que revela um aumento da sistematização do pensamento dos estudantes com consequente redução da fragmentação. Observamos, por exemplo, que Jacira, Leila, Catia e Luciana afirmaram os temas escolhidos (vide Quadro 1) como recursos socionaturais, apontando a importância de cuidados para sua preservação, como um bem comum, necessários para a vida humana e de outros seres. Desse modo, as estudantes procuravam relacionar conteúdos de ensino e temas do sistema de complexos Recursos Socionaturais. A relação dos temas com questões sociais foi uma característica constante de todos os trabalhos. A proposta de Nelson, que vive e trabalha em local onde há exploração de minério como o ouro, é um caso exemplar. Ao trabalhar o tema Água, descreveu ações que visavam

[...] levar o aluno a ver a realidade do rio, mostrar a qualidade da água que é levada para as casas, ver desmatamento, os riscos dos produtos utilizados pela empresa que coleta ouro próximo ao rio, os riscos desses produtos nas águas que irrigam as hortaliças vendidas na feira livre [...] através dessas análises, buscar meios para conservar essas águas limpas até as casas [...]. 
Ao discutir com a comunidade local a possibilidade de atividades econômicas como o garimpo próximo, conduzirem à poluição do rio que abastece a região, assim como as consequências do desmatamento sobre a qualidade das águas, Nelson precisou estabelecer conexão entre conteúdos de diversas naturezas, aproximando-se de um ensino mais condizente com o preconizado pela pedagogia que orientou o curso.

Alguns estudantes também relacionaram os temas escolhidos com aspectos históricos, como Cosme e Liana, que ainda se referiram a questões ambientais. Três estudantes, Lia, Paulo e Leila, citaram o Sistema de Complexos no texto, sem, contudo, empregá-lo claramente no planejamento. Por outro lado, ainda encontramos aqueles que não relacionaram, de nenhum modo, os temas escolhidos aos Recursos Socionaturais, como Vânia e Ana, embora justificassem os temas como necessários e importantes para serem discutidos, inclusive envolvendo a comunidade em que a escola estava inserida.

Enfim, de modo geral, as novas versões das sequências didáticas se mostraram mais fundamentadas em termos de conhecimentos científicos escolares, apresentando conteúdos a serem trabalhados em sala de aula, relacionados aos temas escolhidos.

O desenvolvimento mostrado pelos estudantes entre as duas etapas do planejamento pode ter sido consequência das conversas mantidas durante as entrevistas. A interação com a professora/investigadora que conduziu a entrevista pode ter estimulado a memória acerca do Sistema de Complexos, a necessidade de trabalhar as conexões entre conhecimentos durante o ensino e fortalecido a relação entre ensino e relevância social do tema. Pode, ainda, ter despertado o desejo de revisar os estudos sobre o Sistema de Complexos. O fato é que, após a realização das entrevistas, todos expressaram melhor suas ideias em relação aos aspectos sociais do ensino. Isto nos permite considerar que a discussão serviu para que eles organizassem melhor o pensamento em torno do que já haviam estudado durante o curso e tivessem mais facilidade em expor esses conhecimentos, avançando nas propostas apresentadas.

As discussões e o material didático também podem ter contribuído para a metodologia de ensino, que se apresentou mais bem elaborada, incluindo a aproximação com diferentes áreas do conhecimento, apontando para uma abordagem contextualizada sócio-historicamente. $\mathrm{O}$ apoio encontrado na consulta aos livros didáticos facilitou, certamente, a escolha de conteúdos que se mostraram mais detalhados.

Vale ressaltar que todos os estudantes mostraram a preocupação de que as sequências didáticas propostas pudessem ser aplicadas nos seus locais de trabalho, em salas de aula do Ensino Fundamental e Médio. 


\section{Conclusão}

O Sistema de Complexos está relacionado aos conteúdos que poderão ser trabalhados dentro de temas escolhidos, temas de relevância social, assim como à maneira como esses conhecimentos devem ser tratados visando a compreensão e a atuação na realidade. Desse modo, seria de se esperar que os estudantes estivessem maior clareza para estabelecer relação entre conteúdos, tema e Sistema de Complexos, tendo em vista que todos mostraram a preocupação em discutir questões sociais relevantes, relacionadas aos temas, tendo faltado esclarecer a ligação entre conteúdos/temas/Sistema de Complexos e sua inserção social.

Os resultados mostraram, em síntese, que os estudantes incorporaram apenas parcialmente o Sistema de Complexos Temáticos ao planejamento de ensino. À medida que estes foram sendo construídos, houve um desenvolvimento significativo dos textos que, todavia, não exibiram a esperada relação clara da prática de ensino com a teoria do Sistema de Complexos. O aspecto em que as dificuldades dos estudantes se mostraram mais claramente foi no estabelecimento das relações recíprocas entre as diversas partes dos complexos. De fato, é preciso identificar e discriminar as partes do complexo de modo mais adequado ao tratamento didático, até chegar aos conhecimentos a serem ensinados. Então, é preciso retornar dos conhecimentos escolares ao todo do complexo, para compor uma noção dinâmica da realidade sob estudo. Desse modo, elabora-se uma argumentação de como se chega das partes ao todo e vice-versa. Tentar relacionar conteúdos de diferentes disciplinas para compor o tema do complexo não é o modo mais adequado para se planejar o ensino, pois falta a visão da totalidade para guiar o professor na elaboração do construto final.

Tal conclusão não deve surpreender demasiadamente, pois houve dificuldades em implementar o currículo orientado pelo Sistema de Complexos, posto que a organização curricular da Universidade Federal da Bahia é, preponderantemente, disciplinar e enfrentou-se a impossibilidade de criar novos componentes curriculares e/ou contratar professores com a formação mais próxima da proposta pedagógica do curso, o que demandaria um corpo docente mais afinado com os pressupostos filosóficos e pedagógicos da Licenciatura em Educação do Campo/ UFBA, trazendo mais oportunidades de aplicação desses referenciais, como o Sistema de Complexos Temáticos, na práxis pedagógica dos estudantes.

As dificuldades encontradas apontam para a necessidade de se lutar por condições de trabalho nas Instituições de Ensino Superior que possibilitem outros modos de ensinar e formar professores. Entretanto, o resultado global pode ser considerado positivo, visto que os futuros professores/professoras incorporaram 
questões de natureza social no ensino das ciências naturais, mostrando avanços nesse procedimento, vinculando-o a aspectos mais amplos da realidade.

Trabalhando de acordo com os pressupostos teórico-metodológicos, a exemplo do Sistema de Complexos Temáticos, dentro do referencial do materialismo histórico-dialético, durante a realização das atividades aqui expostas, foi possível mostrar outra maneira de formar professores e professoras para a educação do/no campo, enfatizando os conteúdos científicos escolares, relacionados a questões sociais, visando fornecer elementos para uma melhor compreensão da realidade.

Todavia, devemos ter consciência que, ao acompanharmos a formação de professores e professoras do campo, de duas regiões do Estado da Bahia, realizada pela Faculdade de Educação da Universidade Federal da Bahia, a aplicação de atividades envolvendo um dos pressupostos filosóficos do curso apontado neste artigo, o Sistema de Complexos, não é determinante para a resolução de questões inerentes à formação de professores e professoras, o que demandaria um acompanhamento mais constante a esses profissionais através de formação continuada como suporte e apoio na sua atuação, porém, com certeza, já é um primeiro passo visando contribuir para a melhoria dessa formação.

\section{REFERÊNCIAS}

BRASIL. Ministério da Educação. Resolução CNE/CP 1/2002. Institui Diretrizes Curriculares Nacionais para a Formação de Professores da Educação Básica. Diário Oficial da União, Brasília, 04 mar. 2002, Seção 1, p. 8.

BRASIL. Ministério da Educação. Resolução CNE/CP 2/2015. Define as Diretrizes Curriculares Nacionais para a formação inicial em nível superior (cursos de licenciatura, cursos de formação pedagógica para graduados e cursos de segunda licenciatura) e para a formação continuada. Diário Oficial da União, Brasília, 02 jul. 2015, Seção 1, p. 8-12.

CARVALHO, A. M. P.; GIL-PÉREZ, D. Formação de professores de ciências: tendências e inovações. 10. ed. São Paulo: Cortez, 2011.

CARVALHO, M. S. Realidade da educação no campo e os desafios para a formação de professores da educação básica na perspectiva dos movimentos sociais. Tese (Doutorado) - Faculdade de Educação, Universidade Federal da Bahia, Salvador, 2011.

CUNHA, M. B. M. Formação de professores e professoras no curso de Licenciatura em Educação do Campo/UFBA: área de Ciências da Natureza e Matemática. Tese (Doutorado em Ensino, Filosofia e História das Ciências) - Universidade Federal da Bahia/ 
Universidade Estadual de Feira de Santana, Salvador, 2014.

CUNHA, M. B. M.; SILVA, J. L. P. B.; MORADILLO, E. Pedagogia histórico-crítica e sistema de complexos temáticos: buscando convergências no ensino de ciências. In: ENCONTRO NACIONAL DE PESQUISA EM EDUCAÇÃO EM CIÊNCIAS, 9., 2013, Águas de Lindóia. Atas... [S. 1.]: Abrapec, 2013.

DUARTE, N. Conhecimento tácito e conhecimento escolar na formação do professor (por que Donald Schön não entendeu Luria). Educação \& Sociedade, v. 24, n. 83, p. 601-625, ago. 2003.

FERREIRA, L. H.; KASSEBOEHMER, A. C. Formação inicial de professores de Química: a instituição formadora (re)pensando sua função social. São Carlos: Pedro \& João, 2012.

FREIRE JUNIOR, O. A relevância da filosofia e da história da ciência para o ensino de ciência. In: SILVA FILHO, W. J. (Org.). Epistemologia e ensino de ciências. Salvador: Arcádia, 2002. p. 13-30.

GAMA, C. N. Organização do currículo do curso de Licenciatura em Educação do Campo da Faced/UFBA por áreas de conhecimento. Salvador, [2010?]. Disponível em: $<$ http://www.des.faced.ufba.br/educacampo/educacampo/inter.cambio/termo_coperacao_educa_campo>.Acesso em: 20 out. 2015.

GATTI, B. A. Formação de professores no Brasil: características e problemas. Educação \& Sociedade, v. 31, n. 113, p. 1355-1379, dez. 2010.

KUENZER, A. Z. O trabalho e a formação do professor da educação básica no Mercosul/ Cone Sul. In: TRIVIÑOS, A. N. S.; BÚRIGO, C. C. D.; MARCO, E. A. de; MARTINI, J. G. (Org.). Trabalho e a Formação do Professor de Educação Básica no Mercosul/ Cone Sul. Florianópolis: Imprensa Universitária UFSC, 2012.

LEITE, C. A formação inicial de professores no quadro dos compromissos de Bolonhacontributos para uma reflexão sobre o que foi instituído em Portugal. Revista Brasileira de Pesquisa sobre Formação de Professores, v. 4, n. 7, jul./dez. 2012. Disponível em: $<$ http://formacaodocente.autenticaeditora.com.br/artigo/exibir/12/52/4>. Acesso em: 02 nov. 2015.

LIMA, M. E. C. C.; PAULA, H. F.; SANTOS, M. B. L. Ciências da vida e da natureza no curso de Licenciatura em Educação do Campo - UFMG. In: ROCHA, M. I. A.; MARTINS, A. A. (Org.). Educação do Campo: desafios para formação de professores. Belo Horizonte: Autêntica, 2009.

MALDANER, O. A. A formação inicial e continuada de professores de Química: professores/pesquisadores. Ijuí: Ed. Unijuí, 2003.

MENEZES NETO, A. J. Formação de professores para a Educação do Campo: projetos sociais em disputa. In: ROCHA, M. I. A.; MARTINS, A. A. (Org.). Educação do Campo: desafios para formação de professores. Belo Horizonte: Autêntica, 2009. 
MORADILLO, E. F. A dimensão prática na licenciatura em química da UFBA: possibilidades para além da formação empírico-analítica. Tese (Doutorado em Ensino, Filosofia e História das Ciências) - Instituto de Física, Universidade Federal da Bahia, Salvador, 2010.

PEIXER, Z. I.; VARELA, I. A. Educação do Campo: desafios das pesquisas e políticas. In: PEIXER, Z. I.; VARELA, I. A. (Org.). Educação do Campo. Lages: Grafine, 2011.

PISTRAK, M. Fundamentos da escola do trabalho. São Paulo: Expressão Popular, 2008.

PISTRAK, M. A comuna escolar. São Paulo: Expressão Popular, 2009.

ROCHA, M. I. A. Licenciatura do Campo: histórico e projeto político-pedagógico. In: ROCHA, M. I. A.; MARTINS, A. A. (Org.). Educação do Campo: desafios para formação de professores. Belo Horizonte: Autêntica, 2009.

ROSSO, A. J.; BRANDT, C. F.; CERRI, L. F.; CAMPOS, S. X. de; FREIRE, L. I. F.; TOZETTO, A. S. Novas Diretrizes Curriculares Nacionais para a formação de professores e algumas novas ficções na leitura da escola. Ensaio: Avaliação Políticas Públicas em Educação, v. 18, n. 69, p. 821-84, dez. 2010.

SAVIANI, D. Escola e democracia. 41. ed. Campinas: Autores Associados, 2009.

SAVIANI, D. Formação de professores no Brasil: dilemas e perspectivas. Poíesis Pedagógica, v. 9, n. 1, p. 07-19, jan./jun. 2011.

TAFFAREL, C. N.; COLAVOLPE, R. Sistema de complexo temático: uma contribuição para o debate de reestruturação curricular do curso de Educação Física da UFBA. Rascunho Digital: uma experiência com páginas interativas, Salvador, 2009. Disponível em: <http://www.rascunhodigital.faced.ufba.br/ver.php?idtexto=379>. Acesso em: 24 maio 2012 .

UNIVERSIDADE FEDERAL DA BAHIA. FACED/UFBA. Curso de Licenciatura em Educação do Campo. Projeto Político-Pedagógico. Salvador, 2008. (Não publicado).

Texto recebido em 21 de março de 2016.

Texto aprovado em 16 de maio de 2016. 